\title{
Left out ventriculoperitoneal shunt tubings causing a catastrophe.
}

\author{
Kumar P, Panda SS*, Kumar S \\ Department of Pediatric Surgery, Maulana Azad Medical College, New Delhi, India
}

\begin{abstract}
Ventriculoperitoneal (VP) shunting is a time-tested modality for the treatment of hydrocephalus. Every treatment modality has certain disadvantages, so does VP shunting. Abdominal complications including CSF pseudocyst, knotting, dis-connection or per rectal expulsion are well accounted but small intestinal fistulization and obstruction are extremely rare. We are reporting this case of small intestinal obstruction (volvulus with shunt knotting and small bowel erosion by shunt tubings) in an 8-year-old male child, who underwent shunt revision and previous shunt tubing was left behind in abdomen.
\end{abstract}

Keywords: Ventriculoperitoneal shunt, Shunt tubings, Shunt malfunction, Gut fistulisation, Intestinal obstruction.

Accepted on June 28, 2018

\section{Introduction}

Ventriculoperitoneal (VP) shunt procedure is a common surgery done in field of pediatric and neuro-surgery, with limelight advantages of easy to perform, short learning curve and life saving surgery. VP shunt malfunction is the most common complication seen after surgery, needing shunt revision in most cases. VP shunt tubing may be left behind in body owing to its inert property. When a new shunt tubing is inserted, it can cause problems by mobility of two tubings, along with peristaltic activity of bowel. More than one tubings are likely to cause more complications as happened in presented case. Bowel obstruction and fistulization are relatively rare but life-threatening complications of ventriculoperitoneal shunts, necessitating laparotomy.

\section{Case Report}

The 8-year-old male patient underwent lumbosacral myelomeningocele excision and repair at day 8 of life followed by VP shunting for post-operative hydrocephalus. The patient had shunt malfunction, for which shunt revision was done but previous peritoneal shunt tubing was left behind. He now presented in acute intestinal obstruction viz bilious vomiting, central abdominal distension and obstipation. He underwent emergency exploratory laparotomy which revealed twisted small intestine around shunt tubings and fistulization of shunt into jejunum (Figure 1). The patient was managed by resection of part of jejunum having fistulous connection with the shunt tubing and end to end anastomosis, followed by removal of abdominal part of shunt and exteriorization of shunt.

\section{Discussion}

VP shunting is time tested procedure for hydrocephalus having a short learning curve. On literature review, event-free survival after ventriculo-peritoneal shunt surgery at 1-year ranged from $62 \%$ to $80 \%[1,2]$ and at 10 years from $35 \%$ to $48 \%[1,3]$. The most common shunt complications are malfunction and infection $[4,5]$.
Shunt malfunction is a partial or complete blockage of the shunt. A shunt blockage from blood cells, tissue or bacteria can occur in any part of the shunt.

\section{Shunt infection}

It is usually caused by a person's own skin organisms and the most common infection is Staphylococcus Epidermidis [6], followed by Methicillin resistant Staphylococcus aureus [MRSA] [7].

\section{Over drainage}

It causes the ventricles to decrease in size creating slit-like ventricles as a result of the brain and its meninges pulling away from the skull. Slit ventricles is commonly a problem in young adults who have been shunted since childhood. A particular symptom is severe intermittent headache, often relieved when lying down. Imaging studies reveal smaller than normal ventricles.

\section{Under drainage}

Under drainage fails to relieve the symptoms of hydrocephalus. Surgical treatments include shunt revision (with more accurate pressure valve), ventricular catheters with multiple perforations or openings, craniotomy and fenestration of the intraventricular loculations.
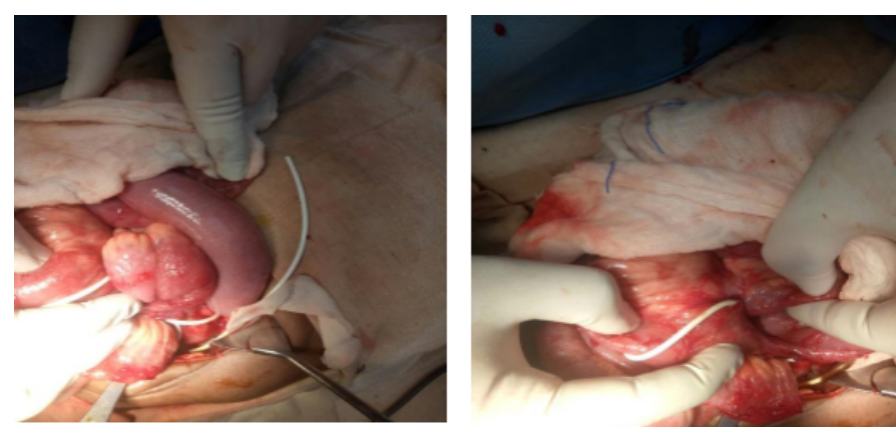

Figure 1. Intra-operative images showing twisted small intestine around shunt tubings and fistulization of shunt into jejunum. 


\section{Abdominal complications}

Abdominal complications of VP shunting include abdominal CSF pseudocyst formation, perforation of GI tract, erosion of solid organs or abdominal wall, disconnection and infection.

Bowel perforation is a rare complication of VP shunt placement, with an incidence rate of $0.1 \%$ to $1 \%$ [8]. Bowel perforation may manifest with non-specific signs and symptoms like fever, leukocytosis, diarrhea or intracranial manifestations like E. coli meningitis [9]. Erosion of VP shunts most commonly seen in stomach and large colon. Small bowel erosion is extremely rare [10]. There have been case reports documenting per anal expulsion of VP shunts after erosion into appendix [11], oral expulsion after gastric erosion [12]. A case has been reported where shunt was extruded through the repaired myelomeningocele area [13]. Clinicians should have a high degree of suspicion of shunt related intra-abdominal complications in children. Clinical examination and radiological studies like X-ray abdomen, ultrasonography and computer tomography may help in making diagnosis. In patients with meningitis, if the CSF analysis reveals organisms seen mainly in gastrointestinal tract, then there should be high degree of suspicion of bowel erosion by the shunt tubing.

The most specific finding for VP shunt erosion seen on VP shunt patency scan includes radiotracer opacification of the bowel with associated peristalsis. Nonspecific findings include central organization of radiotracer in the abdomen [8]. CT of the head may demonstrate hydrocephalus, indicating a shunt malfunction. Air may ascend from the GI tract into the VP shunt resulting in intraventricular air.

Diagnosis and management is mainly by diagnostic laparoscopy and/or laparotomy [14]. Laparoscopy helps in definite visualization of the abdominal end of shunt and fistulization/ knotting or volvulus, and simultaneous removal of the shunt/ exteriorization. In an asymptomatic patient, the shunt tubing should be disconnected at the abdominal wall and removed through the orifice via endoscopy or colonoscopy.

Abdominal pseudocysts, having incidence of $0.25 \%$ to $10 \%$ [15], are diagnosed mainly by ultrasound and management depends on whether infected or not. In absence of infection, simple image guided needle aspiration can be done. If symptoms persist, then shunt revision alone without prior exteriorization can be done. In pseudocysts associated with infection, shunt exteriorization is done followed by infection control. Exteriorization of shunt leads to resolution of pseudocyst, following which shunt again can be peritonialized. Sometimes, if symptoms persist and shunt is needed, then VP shunt may have to be converted to ventriculopleural shunt and rarely ventriculo-atrial shunt.

Spontaneous bacterial peritonitis (SBP) is an infection of the peritoneal fluid in the absence of an obvious intra-abdominal source. While SBP is clearly differentiated from pseudocyst of the abdomen, it may represent a point on the continuum of intra-abdominal processes in the shunted patient. It is proposed that patients with shunts may be predisposed to develop SBP because spinal fluid can behave as an ascitic fluid even in the absence of a peritoneal accumulation [16].

Sclerosing encapsulating peritonitis (SEP) is a rare cause of bowel obstruction, most commonly associated with chronic ambulatory peritoneal dialysis. Two cases of SEP in VP shunting have been described in literature [17]. In each case, the bowel was "cocooned" in a fibrous sheath with a notable absence of parietal adhesions. Both children were managed by meticulous adhesiolysis accompanied by shunt exteriorization.

Volvulus has been cited as the most common cause of VP shuntrelated obstruction [18] and mechanical obstruction due to twisting of the catheter the second most common [19]. Our case had multiple reasons, which may be assigned to acute abdomen presentation. He had twisting of bowel loops around shunt tubings, fistulization into small bowel and entanglement of two shunt tubings. Treatment in most cases is laparotomy.

\section{Conclusion}

Small intestinal obstruction and fistulization are relatively rare but life-threatening complications of ventriculoperitoneal shunts. Isolation of microorganisms from CSF, which mainly reside in gastrointestinal tract, should immediately raise a concern of gut fistulization by the shunt. One should bear in mind the possibility of bowel penetration/fistulization if a patient develops abnormal abdominal conditions, especially in scenario of presence of two tubings.

\section{References}

1. Vinchon M, Baroncini M, Delestret I. Adult outcome of pediatric hydrocephalus. Childs Nerv Syst. 2012;28:84754.

2. Kestle J, Drake J, Milner R, et al. Long-term followup data from the shunt design trial. Pediatr Neurosurg. 2000;33:230-6.

3. Sainte-Rose C, Hoffmann HJ, Hirsch JF. Shunt failure. Concepts Pediatr Neurosurg. 1989;9:7-20.

4. Reddy, Kesava G. Ventriculoperitoneal shunt surgery and the risk of shunt infection in patients with hydrocephalus: Long-term single institution experience. World Neurosurg. 2011;78:155-63.

5. Borgbjerg BM, Gjerris F, Albeck MJ, et al. Frequency and causes of shunt revisions in different cerebrospinal fluid shunt types. Acta Neurochir (Wien) 1995;136:189-94.

6. Wong GK, Ip M, Poon WS, et al. Antibiotics-impregnated ventricular catheter versus systemic antibiotics for prevention of nosocomial CSF and non-CSF infections: A prospective randomized clinical trial. J Neurol Neurosurg Psychiatry. 2010;81:1064-7.

7. Bayston R. Epidemiology, diagnosis, treatment, and prevention of cerebrospinal fluid shunt infections. Neurosurg Clin N Am. 2001;12:703-8.

8. Bourm K, Pfeifer C, Zarchan A. Small bowel perforation: A rare complication of ventriculoperitoneal shunt placement. J Radiol Case Rep. 2016;10(6):30-5.

9. Sathyanarayana S, Wylen EL, Baskaya MK, et al. Spontaneous bowel perforation after ventriculoperitoneal shunt surgery: Case report and a review of 45 cases. Surgical Neurology. 2000;54(5):388-96.

10. Odebode TO. Jejunal perforation and peroral extrusion of a 
peritoneal shunt catheter. British Journal of Neurosurgery. 2007;21(2):235-6.

11. Matsuoka H, Takegami T, Maruyama D, et al. Trans anal prolapse of a ventriculoperitoneal shunt catheter. Neurologia medico-chirurgica. 2008;48(11):526-8.

12. Ghritlaharey RK. Review of the management of peroral extrusion of ventriculoperitoneal shunt catheter. J Clinical Diag Res. 2016;10(11)2:1.

13. Aras M, Altaş M, Serarslan Y, et al. Protrusion of a peritoneal catheter via abdominal wall and operated myelomeningocele area: A rare complication of ventriculoperitoneal shunt. Childs Nerv Syst. 2013;29(7):1199-202.

14. Vinchon M, Baroncini $M$, Laurent $T$, et al. Bowel perforation caused by peritoneal shunt catheters: Diagnosis and treatment. Neurosurgery. 2006;58:76-82.
15. Birbilis T, Kontogianidis K, Matis G, et al. Intraperitoneal cerebrospinal fluid pseudocyst: A rare complication of ventriculoperitoneal shunt. Chirurgia. 2008;103(3):351-3.

16. Gaskill SJ, Marlin AE. Spontaneous bacterial peritonitis in patients with ventriculoperitoneal shunts. Pediatr Neurosurg. 1997;26(3):115-9.

17. Sigaroudinia MO, Baillie C, Ahmed S, et al. Sclerosing encapsulating peritonitis: A rare complication of ventriculoperitoneal shunts. J Pediatr Surg. 2008;43(5):e31-3.

18. Bal RK, Singh P, Harjai MM. Intestinal volvulus: A rare complication of ventriculoperitoneal shunt. Pediatr Surg Int. 1999;15(8):577-8.

19. Starreveld Y, Poenaru D, Ellis P. Ventriculoperitoneal shunt knot: A rare cause of bowel obstruction and ischemia. Can J Surg. 1998;41(3):239-40.

\section{*Correspondence to:}

Dr. Shasanka Shekhar Panda

Department of Paediatric Surgery

Maulana Azad Medical College

New Delhi-110002,

India

Tel: +91 9873542072

Email: drshasank_aiims@yahoo.co.in 